\title{
Analysis on Influencing Factors of the Tourism Consumption of Rural Residents \\ Hong Jin
}

Henan Polytechnic, Zhengzhou, 450046, China

\begin{abstract}
Due to the continuous development of agricultural production efficiency and adjustment of agricultural production structure in China, the discretionary income and leisure time of rural residents have been improved and the consumption also has changed, which further improve their tourism demand. At present, the rural residents' tourism consumption demand has become an important strategy for the development of tourist industry in the future in China. Based on this, the influencing factors of the tourism consumption of rural residents are discussed in this paper.
\end{abstract}

Key words: Rural residents; tourism consumption; influencing factors

Compared with the urban residents, the tourism of rural residents has always accounted for a low proportion; however, with the continuous development of rural construction, the consumption level and income of rural residents have been improved greatly and they are more and more eager to go out for traveling. As the tourism is spontaneous, disperse and free and there are objective factors that affect the sound development of rural tourism, it is crucial to analyze the influencing factors of the tourism consumption of rural residents.

\section{Features of rural residents' tourism}

According to the investigation and statistics, the rural residents have the following features in traveling: (1) the main purpose of traveling is mainly to visit relatives and friends and for tour and sightseeing; (2) rural residents know less about the tourism industry and lack of corresponding tourist experiences, so they pay more attention to the economical efficiency of tourism and have low requirements on comfort; (3) it is found by the survey of rural residents that the rural residents pay 
more attention to the price of tourism products and have low requirements on the high-grade products. As the traveling of most rural residents is mainly to visit relatives and friends, so their expense for accommodation and meals is less and their expense for shopping is more; (4) according to the statistics, compared with the consumption level of urban residents, the tourism consumption of rural residents per capital is very low, only accounting for $33.3 \%$ of the tourism consumption of urban residents; (5) rural residents prefer the famous scenic spots and historic sites and large cities, such as Shanghai and Beijing and mainly choose coach and train as the basic transportation means. In addition, the tourist propaganda strength is insufficient and the corresponding tourism service institutions are lacked in rural areas and the corresponding organization is lacked during tourism; (6) independent travel accounts for a large proportion and the range of tourism is not limited to the province; (7) the rural residents going out for traveling have a low degree, in which 26 63-year-old residents account for $73 \%$ of the overall number of people and 26 43-year-old rural residents account for $45.7 \%$ of the overall number of people; (8) rural residents know the tourism information mainly by the introduction of friends or TV and only few rural residents find the relevant information on the Internet or consult the travel agency.

\section{Main cause for the influence on rural residents' tourism consumption}

\subsection{Traditional consumption concept of rural residents}

The tourism consumption concept of rural residents is generally traditional and still affected by small-scale production mode and adheres to the "diligent and thrifty" consumption mode and consumption concept in China, which is greatly different from the prevailing credit consumption in the city. The cautious tourism consumption attitude restricts the tourism consumption desire of rural residents. With low desire for cultural consumption, more rural residents pay attention to the economical and substantial material and cultural consumption that can play a certain role in the life.

The backward consumption concept is also a key factor for the low tourism consumption of rural residents 


\subsection{Non-perfect social security and low income of rural residents}

The state has reduced the agricultural tax and further increased the agricultural input since 2003, thus creating objective conditions of improving the farmers' income. According to the data survey, the income per capital of rural residents is just 31.8 of that of urban residents. The income of urban residents mainly comes from the monetary income and the income of rural residents comes from material object in addition to the monetary income. The income of rural residents is mainly used for saving, consumption and production input and that of urban residents is used for investment in addition to saving and consumption. It is these factors that lead to the low tourism consumption ability of rural residents with low income. In addition, the social security of rural residents in China is not perfect and the rural residents consider the schooling problem of their child and their pension first, so they have low demand for tourism.

\subsection{Lacking of spare time}

There are busy season and slack season in rural areas, but the rest day and working day are not distinguished obviously and rural residents have to do farm works, such as fattening, weeding and rear livestock in pens, which should be done every day and not be delayed. In addition, a large part of rural residents go out to work to subsidize the household. Therefore, rural residents go out for traveling in a selected time and the family travel is rare because someone must take care of the things at home.

\subsection{Backward consumption environment}

With the continuous social development, the basic transport infrastructures are greatly improved in rural areas. However, compared with the city, there is still a great space for improvement. The increase of infrastructure greatly changes the lifestyle and production mode of rural areas. Therefore, it is required to increase the construction of transport infrastructure ruing rural construction. Besides, the state has improved the supervision on the consumption environment and tourism market of rural tourism, but there are still serious price fraud, low service quality and other circumstances in tourism. 


\section{Formulation of policy promoting rural residents' tourism}

To promote the traveling of rural residents, a system should be established, which needs the efforts of consumers, tourism unit and government. The corresponding policy is formulated in this paper mainly from tourism enterprise and government.

\subsection{Formulation of policy of tourism enterprise}

\subsubsection{Development of products according to the market features}

At present, the tourism market of rural residents in China is not perfect and in the initial stage and most rural residents still stay in the initial tour and sightseeing stage and have low requirements on the tourism. Therefore, in launching the corresponding tourism products, the scenic spots and famous tourist areas in the big cities and province should be taken as the support of tourism products and the elements of transportation, shopping and traveling should be taken as the important supports of tourism products so as to develop the products that conform to the rural residents' tourism consumption demand and psychology.

At present, the following special tourism products can be launched: (1) urban sight tour. The farmers can be organized to take a tour in the big cities to see the beautiful scenery, architectural style, developed science and technology and cultural relics with a long history. In addition, many rural residents are eager to enjoy the advanced service facilities, shopping environment and business environment in the city. Therefore, to better cater to the demand of rural residents, the travel agency can develop some characteristic tourism products according to the demands of rural residents at these aspects; (2) model-type rural tour. With the continuous development of rural construction, many countries initiate a boom of striving for well-off life and taking a path to wealth and may rural residents hope to learn the experience about how to be rich at other developed countries. Therefore, the travel agency can organize the rural residents to conduct high-yield sideline, star village and town and other tourism projects; (3) newly-married honeymoon tour. With the continuous development of rural economy, the thought of rural youth is changed and many new-married couples are willing to conduct a wedding tour. Therefore, the tourism 
enterprise can develop the wedding tour product according to the requirements of newly-married couple; (4) incentive tour. All the parents hope their child can get good academic performance and many parents often choose a tour as the incentive of reading and learning. In addition, the traveling of parents with their child plays a role in increasing the child's knowledge and relaxing the child's mind. Therefore, the travel agency can development products according to this demand so as to better adapt to the tourism demand of college students.

\subsubsection{Change the consumption concept of farmers}

The consumption habits of rural residents impose great influences on their consumption behavior. To further improve the tourism consumption habits of rural residents, it is required to change the consumption concept of rural residents and guide the rural residents with modern consumption concept to make them have modern consumption awareness.

According to the survey, the farmers know the tourism information mainly by newspaper, TV, introduction of friends and other simple channels and the travel agency fails to give play to its auxiliary and propaganda role in guiding the tourism decision of rural residents, so most farmers do not know the features of scenic spots, whether it is worthy of traveling and attentions in the tour and then choose the conservative traveling mode and spend conservatively. To effectively transmit the tourism information, the tourism enterprise should improve the tourism propaganda strength of farmers and improve the rural residents' tourism awareness. To further stimulate the tourism interest of rural residents, it is allowed to design the tourism advertising focusing on learning the experience of being rich and improving the knowledge. In addition, the tourism enterprise can cooperate with the local government to conduct tourism propaganda regularly in rural areas.

\subsection{Formulation of policy at government level}

\subsubsection{Improve the environment of rural tourism market}

The government should further improve the construction strength of communication network, power grid and water network in rural areas so as to change the potential demand of rural residents into realistic productivity and expand the 
farmers' income channel. In addition, there is almost no specialized travel agency in rural areas, so the consultation and application of rural residents are difficult. Therefore, the government can take proper measures to encourage the travel agency to set up specialized service outlet in rural areas, responsible for the tourism application and consultation of farmers.

To eliminate the worries of rural residents in traveling, it is required to vigorously propagandize the cheap tourism products, ensure the security of good, hygiene, transportation and other aspects of farmers in traveling, do the complaint handling service well and seriously punish the tourist cheat and overcharge and other behaviors.

\subsubsection{Improve the basic income of rural residents}

The main cause for the backward development of the tourism consumption of rural residents is the lacking of perfect social security system and low income of rural residents. To further improve the tourism consumption of rural residents, the income level of farmers should be improved. The government should vigorously develop the agriculture industrialization operation, encourage the farmers to conduct deep processing of agricultural products to improve the added value of agricultural products, cultivate the leading township enterprises with a large area covered and strong driving force, deeply reform the grain distribution system, further perfect the grain macro regulation system, improve the farmers' economic income and develop the village into small town. In addition, the government should also take social medical insurance and social pension insurance as an important development direction of rural social security system in the future to solve the worry of farmers essentially and promote the current consumption of farmers.

\section{Conclusion}

In conclusion, the tourism of rural residents is a market with great development potential and an effective way to expand the internal demand. The different regions can develop feasible and effective tourism policy according to its actual situation in rural areas and surrounding tourism resources. In addition, the government should guide the farmers to change their consumption concept and take a series of policy 
measures to promote the development of the tourism consumption of rural residents.

\section{References:}

[1] Zhong Shi'en, Zhang Jie, Zhou Qiang et al. Spatial Centrality of Domestic Tourism of Rural Residents[J]. Geographical Research, 2009, 28(6): 1562-1571.

[2] Tang Daijian, Pan Junbin. Empirical Research on Tourism Consumption Problem of Rural Residents in China and Its Countermeasures[J]. Jiangsu Commercial Forum, 2010, (6): 106-108.

[3] Zhao Dongxi, Liu Yongjuan. Research on Influencing Factors of the Tourism Consumption of Rural Residents[J]. Tourism Forum, 2010, 3(2): 23-27. 